\title{
Fluctuating Asymmetry of Finger Lengths, Digit Ratio (2D:4D), and Tattoos: A Pre-Registered Replication and Extension of Koziel et al. (2010)
}

Tinisha Osu ${ }^{1}$, Julia Lechler-Lombardi ${ }^{1}$, Amy Butler ${ }^{1}$, Miles Newman ${ }^{1}$, Karolina Miłkowska ${ }^{2}$, Andrzej Galbarczyk ${ }^{2, \dagger}$, and Gareth Richards ${ }^{1, \dagger, *}$

${ }^{1}$ School of Psychology, Faculty of Medical Sciences, Newcastle University, UK

${ }^{2}$ Department of Environmental Health, Faculty of Health Science, Jagiellonian University Medical College, Poland

${ }^{\dagger}$ Authors contributed equally

* Corresponding author address: School of Psychology, Newcastle University, 2.27 Ridley Building 1, Queen Victoria Road, Newcastle upon Tyne, UK; email: gareth.richards@ncl.ac.uk

\section{Highlights}

- Tattoos may be associated with prenatal testosterone and used as fitness indicators

- Koziel et al. (2010) reported increased bodily symmetry in tattooed males

- We broadly replicate this previous finding in a large sample from the UK and Poland

- Number of tattoos correlated positively with fluctuating asymmetry in females

- Digit ratio (2D:4D) and tattoos were not associated when covariates were controlled

\begin{abstract}
Background: Tattoos bring risks yet no obvious evolutionary benefit. Koziel et al. (2010) reported increased fluctuating symmetry (a proxy for low developmental instability) in tattooed men, suggesting they could serve as fitness indicators.

Aims: We replicate and extend the findings of Koziel et al. by examining fluctuating asymmetry of finger lengths and digit ratio (2D:4D) (a putative indicator of prenatal testosterone exposure) as predictors of adult tattoos prevalence.
\end{abstract}

Study design: We used an online survey with a correlational design. 
Subjects: Participants were recruited from the UK and Poland via university participant pools and social media. Data were available for presence/absence of tattoos and at least one predictor variable (composite Fluctuating Asymmetry [cFA], right-hand digit ratio [R2D:4D] and lefthand digit ratio [L2D:4D]) for $\mathrm{n}=186$ males and $\mathrm{n}=997$ females.

Outcome measures: We firstly assessed presence/absence of tattoos; when at least one tattoo was present, we also examined overall number and highest visibility.

Results: Greater cFA was associated with lower likelihood of having tattoo in males, though in females greater cFA was associated with higher numbers of tattoos. R2D:4D and L2D:4D correlated negatively with number of tattoos in males, and a positive correlation between L2D:4D and number of tattoos was observed in females. However, these latter findings did not remain significant after controlling for covariates.

Conclusions: Tattoos may act as fitness indicators in males, though this explanation appears not to extend to females. Prenatal testosterone may also play a role, though doubt is cast on this premise because 2D:4D effects did not remain statistically significant after controlling for covariates.

Keywords: 2D:4D; Developmental instability; Digit ratio; Fluctuating asymmetry; Tattoos; Testosterone 


\section{Introduction}

Tattoos are a form of body modification in which markings to the skin are made via insertion of pigment (i.e. 'ink') into the dermis. Such procedures are known to have existed for many thousands of years [1], with one of the earliest and most well-known tattooed individuals being Ötzi the Iceman [2]. Tattoos have sometimes been linked to membership of counter-cultures (e.g. punks, goths, motorcyclists, gang members), prisoners, and the military, and associated with lower social classes and deviance $[3,4]$. However, such stereotypes are outdated, and in recent years tattoos have gained in popularity within mainstream culture and fashion.

Tattooing can result in adverse outcomes including allergic reactions, acute inflammatory responses, scarring, and bloodborne diseases [5,6]. Furthermore, barring expensive, painful, and time-consuming procedures (e.g. laser removal), tattoos are permanent, and many people experience regret. From an evolutionary perspective, voluntarily partaking in such behaviour would be considered maladaptive if there were no compensatory fitness benefit. One possibility is that tattoos serve the function of accentuating attractive body parts to potential mates and/or as a means of hiding perceived shortcomings in appearance [7]. Another idea is that they act as an honest signal of biological quality [7-10], i.e. in accordance with Zahavi's [11] handicap principle. The general premise is that those with high biological quality would be more likely to survive the process of getting tattooed, and so, might be more willing to incur the risks in order to signal their biological quality to potential mates and intrasexual rivals. With this hypothesis in mind, it is worth considering that, although throughout most of modern Europe the likelihood of experiencing severe/life-threatening complications as a result of getting tattooed is generally very low, the case may have been quite different in the ancestral environment in which this behaviour first evolved.

If tattoos do act as fitness indicators, it is of interest to consider their biological correlates. Developmental instability (DI) is an organism's inability to develop an ideal phenotype when challenged by environmental and genetic insults. DI can be approximated by measuring fluctuating asymmetry (FA), the random deviations from perfect bilateral symmetry observed for paired traits $[12,13]$. Although doubts have been expressed regarding the utility of FA as a proxy for DI (see e.g. [14,15]), it has frequently been employed in human research [16-19], and is known to predict health/disease, psychological, reproductive, and physical attractiveness outcomes [18]. Koziel et al. [8] reported that tattooed males $(n=64)$ were more symmetrical 
than non-tattooed males $(\mathrm{n}=38)(p=0.002, d=0.659)$, and that there was a similar (but nonsignificant) difference between tattooed females $(n=52)$ and non-tattooed females $(n=48)(p=$ $0.1, d=0.333$ ). This could imply that tattooed males have relatively low DI, and that their tattoos are used as a means of signalling biological quality to potential mates and intrasexual rivals.

Others have suggested that androgens may be associated with the propensity for getting tattoos $[20,21]$. One possibility is that exposure to high levels of prenatal testosterone organises the brain in a manner that increases the likelihood of pursuing risky behavioural strategies in adult life. As measuring prenatal testosterone is notoriously difficult, researchers often rely on a putative marker, the ratio of length between the second and fourth fingers (digit ratio or 2D:4D) [22]. Although questions abound regarding the validity of this measure [23,24], a recent metaanalysis reported significant correlations between 2D:4D and risky/impulsive behaviour in both males and females [25]. It therefore seems plausible that 2D:4D could be a predictor of adult behaviour relating to tattoos.

We present a pre-registered (https://osf.io/9zxty) study to examine links between tattoos, FA, and 2D:4D. We hypothesised that having (as opposed to not having) tattoos, having increasing numbers of tattoos, and having increasing visibility of tattoos, would all be associated with low FA and low (i.e. 'male-typical') 2D:4D ratios.

\section{Materials and methods}

2.1 Participants: We performed a priori power calculations using G*Power 3.1 [26,27] to determine the sample sizes required to observe statistically significant effects with $\alpha$ set at $p<$ 0.05 and $80 \%$ statistical power. Based on effect sizes from Koziel et al. [8] (calculated by the current authors), and assuming that approximately $25 \%$ of participants would have at least one tattoo [28], samples of $n=116$ (males) and $n=446$ (females) would be required to detect statistically significant differences between tattooed and non-tattooed participants if using twotailed independent samples $t$ tests. It should be noted, however, that some of the analyses reported here exceed these suggested sample sizes; this is because data were collected as part of a larger study examining tattoos, personality and birth order, for which a bigger sample was required (see OSF page for details). Analyses presented are restricted to those participants who answered whether or not they had at least one tattoo and for whom we had usable data for at least one of FA, R2D:4D or L2D:4D ( $\mathrm{n}=186$ males, $\mathrm{n}=997$ females). 
2.2 Apparatus/Materials: Participants provided demographic information (sex, age, ethnicity, sexual orientation, country of residence, perceived socioeconomic status) before being asked whether they had any tattoos. If the participant reported having tattoos, they were then asked to specify the overall number (response options: 0-99+), which is known to correlate very strongly with the percentage of body coverage ( $r=0.90$; [29]), as well as highest visibility (1 $=$ 'Rarely visible', 2 = 'Only visible in underwear or bathers', $3=$ 'Visible in shorts, $\mathrm{t}$-shirt and open shoes', 4 = 'Visible in long pants, long sleeves and covered shoes', or 5 = 'Always visible') [30]. Subjective socioeconomic status was measured using a single-item ('My family's social status is very high', anchored at 0 ['Strongly disagree'] and 10 ['Strongly agree']) developed by Leung and $\mathrm{Xu}[31]$.

Participants followed instruction from the BBC Internet Study [32] to self-measure their second (2D) and fourth (4D) digits on each hand. To reduce the effect of outliers, we followed the guidance of Peters et al. [33] by restricting the range of finger lengths to $50-100 \mathrm{~mm}$; we then calculated 2D:4D by dividing 2D by 4D (for each hand separately), and restricted the range of scores to 0.80-1.20. Composite FA (cFA) was calculated from 2D and 4D lengths (range restricted to $50-100 \mathrm{~mm}$ ) in accordance with Voracek (p.107) [34]:

$$
c F A=\frac{\frac{\sum d \cdot|R d-L d|}{\left[\frac{R d+L d}{2}\right]}}{2}
$$

In this formula, $d=2 \mathrm{D}$ and $4 \mathrm{D}$ length, and is expressed as a percentage of trait size. In other words, this is the sum of right $2 \mathrm{D}$ and $4 \mathrm{D}$ length multiplied by the absolute value of the difference between sum of right and left $2 \mathrm{D}$ and $4 \mathrm{D}$ length $\left(\sum \mathrm{d}|\mathrm{Rd}-\mathrm{Ld}|\right)$ divided by mean right and left $2 \mathrm{D}$ and 4D length $((\mathrm{Rd}+\mathrm{Ld}) / 2)$ and divided by 2 .

2.3 Design and Procedure: A correlational design was used; cFA, R2D:4D, and L2D:4D were predictors, and presence/absence, overall number, and highest visibility of tattoos were outcomes. Participants completed an online survey (hosted by Qualtrics) presented in either English or Polish, and provided informed consent before beginning the study. The survey was advertised via research participation schemes at xxxx University and xxxx University in $\mathrm{xxxx}$, as well as more widely on British and Polish social media. Ethical approval was granted by the Faculty of Medical Sciences Research Ethics Committee, xxxx University (reference no: 17061/2018), and all procedures were conducted in accordance with the Declaration of Helsinki. The hypotheses and analysis plan were pre-registered on the Open Science 
Framework (OSF) (https://osf.io/9zxty), and statistical tests were conducted using Statistica 12.0 .

2.4 Statistical analysis: We conducted univariate analyses using independent samples $t$ tests, simple regression, and Spearman's correlations. We then followed-up with multivariate analyses (binary logistic regression, multiple regression, and non-parametric partial correlations) in which we controlled for participant age (continuous), sexual orientation $(1=$ heterosexual, 2 = homosexual, 3 = bisexual, or 4 = other), subjective socioeconomic status (continuous; higher scores indicate higher SES), and survey language $(1=\text { English, } 2=\text { Polish })^{1}$. Although not specified in the pre-registration, we also used Poisson regression models with a log link function when examining number of tattoos due to the variable exhibiting considerable positive skew.

\section{Results}

The majority of participants $(\mathrm{n}=884,74.7 \%)$ completed the survey in Polish, whereas the rest $(\mathrm{n}=299,25.3 \%)$ completed it in English. Participants were predominantly females $(\mathrm{n}=787,89.0 \%$ in the Polish subsample and $n=210,70,2 \%$ in UK subsample). Ages ranged from 18 to 77 ( $M$ $=25.62, S D=9.521)$, and most participants were White $(\mathrm{n}=1151,97.3 \%)$ and had at least one tattoo $(n=834,70.5 \%)$. In the Polish subsample, 80.7\% $(n=635)$ of females and $77.3 \%(n=75)$ of males had at least one tattoo. In the UK subsample, $45.7 \%(\mathrm{n}=96)$ of females and $31.5 \%$ $(n=28)$ of males had at least one tattoo. Within the tattooed subsample, the number of tattoos reported ranged from 1 to $68(\mathrm{n}=828, M=5.21, S D=6.623$; note $\mathrm{n}=6$ missing values). Although predominantly heterosexual $(n=863,73.0 \%)$, the sample included a higher representation of other sexual orientations (homosexual, $n=57$ [4.8\%]; bisexual, $n=235$ [19.9\%]; other, $\mathrm{n}=28$ [2.4\%]) than typically reported in adult populations from the UK [35] and Poland [36,37]. Following the protocol proposed by Peters et al. [33], we were able to calculate R2D:4D for 990 females and 182 males, L2D:4D for 978 females and 181 males, and cFA for 309 females and 121 males.

Paired samples $t$ tests detected no directional asymmetry for $2 \mathrm{D}, t_{(1191)}=0.243, p=0.808$, or $4 \mathrm{D}, t_{(1188)}=0.926, p=0.355$, so we computed cFA using the equation specified earlier. Digit

\footnotetext{
${ }^{1}$ Please note that in the pre-registered analysis plan we also specified that we would include ethnicity $(1=$ White, 2 = not White) as a covariate: however, due to the very low number of non-White participants, this covariate was not entered into any of the analyses reported here.
} 
ratio was lower in males than females for both R2D:4D and L2D:4D, females were more likely than males to have at least one tattoo, $\chi^{2}(1,1183)=24.267, p<0.001, \varphi=0.143$, and there was no sex difference for cFA (Table 1).

Table 1. Digit Ratio (2D:4D) and fluctuating asymmetry of finger lengths among females and males

\begin{tabular}{|c|c|c|c|c|c|c|c|c|c|}
\hline & \multicolumn{3}{|c|}{ Females } & \multicolumn{3}{|c|}{ Males } & & & \\
\hline & $\mathrm{n}$ & $\mathrm{M}$ & $\mathrm{SD}$ & $\mathrm{n}$ & $\mathrm{M}$ & SD & $t$ & $p$ & $d$ \\
\hline R2D:4D & 990 & 1.006 & 0.057 & 182 & 0.994 & 0.064 & -2.420 & 0.016 & -0.206 \\
\hline L2D:4D & 978 & 1.005 & 0.052 & 181 & 0.995 & 0.060 & $-2.033 *$ & 0.043 & -0.188 \\
\hline cFA & 309 & 0.459 & 0.358 & 121 & 0.442 & 0.336 & -0.966 & 0.334 & -0.048 \\
\hline
\end{tabular}

* equal variances not assumed

At the univariate level, paired samples $t$ tests detected that tattooed and non-tattooed participants did not differ in cFA, R2D:4D, or L2D:4D (Table 2). However, when controlling for covariates (participant age, sexual orientation, socioeconomic status, and survey language) in a binary logistic regression model, cFA was significantly associated with the probability of having tattoo among males. Higher cFA had a negative association with the likelihood of having tattoo in males, though there was no such effect in females; digit ratio was not significantly associated with the probability of having tattoo (Table 3 ).

Table 2. Digit Ratio (2D:4D) and fluctuating asymmetry of finger lengths among tattooed and non-tattooed females and males

\begin{tabular}{|c|c|c|c|c|c|c|c|c|c|c|c|c|c|}
\hline & & \multicolumn{3}{|c|}{ Females } & \multirow[b]{2}{*}{$t$} & \multirow[b]{2}{*}{$p$} & \multirow[b]{2}{*}{$d$} & \multicolumn{3}{|c|}{ Males } & \multirow[b]{2}{*}{$t$} & \multirow[b]{2}{*}{$p$} & \multirow[b]{2}{*}{$d$} \\
\hline & & $\mathrm{n}$ & M & SD & & & & $\mathrm{n}$ & $\mathrm{M}$ & SD & & & \\
\hline \multirow[t]{2}{*}{ R2D:4D } & Tattooed & 726 & 1.006 & 0.056 & \multirow{2}{*}{0.504} & \multirow{2}{*}{0.614} & \multirow{2}{*}{-0.035} & 101 & 0.995 & 0.060 & \multirow{2}{*}{0.100} & \multirow{2}{*}{0.920} & \multirow{2}{*}{-0.016} \\
\hline & Non-tattooed & 264 & 1.004 & 0.058 & & & & 81 & 0.994 & 0.068 & & & \\
\hline \multirow[t]{2}{*}{ L2D:4D } & Tattooed & 716 & 1.006 & 0.052 & \multirow{2}{*}{0.685} & \multirow{2}{*}{0.494} & \multirow{2}{*}{-0.058} & 102 & 0.991 & 0.058 & \multirow{2}{*}{-1.120} & \multirow{2}{*}{0.264} & \multirow{2}{*}{0.169} \\
\hline & Non-tattooed & 262 & 1.003 & 0.052 & & & & 79 & 1.001 & 0.061 & & & \\
\hline \multirow[t]{2}{*}{ cFA } & Tattooed & 228 & 0.458 & 0.373 & \multirow{2}{*}{-0.078} & \multirow{2}{*}{0.938} & \multirow{2}{*}{0.008} & 65 & 0.412 & 0.356 & \multirow{2}{*}{0.368} & \multirow{2}{*}{0.713} & \multirow{2}{*}{0.065} \\
\hline & Non-tattooed & 81 & 0.461 & 0.318 & & & & 56 & 0.434 & 0.313 & & & \\
\hline
\end{tabular}


Table 3. Digit Ratio (2D:4D) and fluctuating asymmetry of finger lengths and the likelihood of having tattoos, after controlling for participant age, sexual orientation, socioeconomic status, and survey language

\begin{tabular}{|l|l|l|l|l|l|l|}
\hline & & $\mathbf{B}$ & $\mathbf{S E}$ & $\mathbf{O R}$ & $\mathbf{9 5 \%}$ CI & $\boldsymbol{p}$ \\
\hline R2D:4D & Females & 1.834 & 1.762 & 6.256 & $0.198,198.0$ & 0.298 \\
\hline & Males & 0.735 & 3.800 & 2.086 & $0.001,3582$ & 0.847 \\
\hline L2D:4D & Females & 2.154 & 1.923 & 8.620 & $0.199,373.4$ & 0.263 \\
\hline & Males & -3.509 & 3.824 & 0.030 & $0.000,53.82$ & 0.359 \\
\hline cFA & Females & 0.106 & 0.495 & 1.112 & $0.422,2.934$ & 0.830 \\
\hline & Males & $\mathbf{- 1 . 9 6 2}$ & $\mathbf{0 . 9 0 6}$ & $\mathbf{0 . 1 4 1}$ & $\mathbf{0 . 0 2 4 , 0 . 8 3 0}$ & $\mathbf{0 . 0 3 0}$ \\
\hline
\end{tabular}

Within the group of males with at least one tattoo, univariate regressions detected significant associations between number of tattoos and cFA $(b=0.331, p=0.012), \mathrm{R} 2 \mathrm{D}: 4 \mathrm{D}(b=-1.869$, $p=0.005)$, and L2D:4D $(b=-1.514, p=0.027)$. However, after controlling for participant age, sexual orientation, socioeconomic status, and survey language, multiple regression models detected no significant associations between number of tattoos and cFA $(b=0.144, p=0.389)$, R2D:4D $(b=1.636, p=0.088)$, or L2D:4D $(b=0.983, p=0.303)$.

Within the group of females with at least one tattoo, simple models demonstrated no relationship between number of tattoos and cFA $(b=0.112, p=0.145)$, or R2D:4D $(b=0.324$, $p=0.273$ ). A significant relationship between number of tattoos and L2D:4D was observed in the univariate regression $(b=0.694, p=0.030)$ but not in the multivariate model $(b=0.327, p$ $=0.416)$, after controlling for participant age, sexual orientation, socioeconomic status, and survey language. At the multivariate level, a significant, positive relationship was observed between cFA and number of tattoos $(b=0.338, p=0.003)$, after controlling for participant age, sexual orientation, socioeconomic status, and survey language.

Within the tattooed subsample, no associations were observed between visibility of tattoos and cFA (males: $r h o_{[63]}=0.113, p=0.370$; females: $r h o_{[226]}=0.063, p=0.343$ ), R2D:4D (males: rho ${ }_{[99]}=-0.033, p=0.744$; females: $\left.r h o{ }_{[724]}=0.001, p=0.974\right)$, or L2D:4D (males: $r h o$ [100] $=-0.135 p=0.175$; females: rho $\left.{ }_{[714]}=0.021, p=0.572\right)$ in non-parametric Spearman's correlation models. Non-parametric partial correlations (controlling for age, sexual orientation, SES, and survey language) showed no significant associations: $\mathrm{cFA}$ (males: $r h o_{\text {partial }}{ }_{[36]}=$ 0.098, $p=0.559$; females: $r h o_{\text {partial [129] }}=0.025, p=0.778$ ); R2D:4D (males: $r o_{\text {partial }}^{[62]}=$ - 
0.009, $p=0.942$; females: $r h o_{\text {partial }[452]}=-0.028, p=0.556$ ); L2D:4D (males: $r h o_{\text {partial }}[63]=$ $0.046, p=0.713$; females: $r h o_{\text {partial }[445]}=-0.020, p=0.677$ ).

\section{Discussion}

The current study aimed to explore whether tattoos act as honest signals of biological quality in line with the handicap principle [11]. The basic idea is that in the environment of evolutionary adaptedness, those with high biological quality would have been more likely to survive the tattooing procedure/associated complications, and so may have been more willing to incur the risks in order to advertise their biological quality to potential mates and intrasexual rivals. For the current study, we examined associations with developmental instability (DI) and prenatal testosterone exposure via two proxy indicators: Fluctuating asymmetry (FA) and digit ratio (2D:4D). Although FA and the presence/absence of at least one tattoo were unrelated at the univariate level, tattooed males were found to have lower FA than non-tattooed males once covariates had been controlled for. This broadly replicates the finding of Koziel et al. [8]. However, we also observed a positive correlation between FA and number of tattoos in females, a finding which suggests sex differences in the association between DI and the propensity to get tattoos. Additionally, number of tattoos was negatively correlated with R2D:4D and L2D:4D in men and positively correlated with L2D:4D in women. Although this might imply involvement of prenatal sex hormone exposure, doubt is cast on this premise because the relationships did not retain statistical significance once covariates had been controlled for.

The finding that tattooed males had lower FA compared to non-tattooed males may have a plausible evolutionary explanation in terms of signalling fitness-related traits (e.g. low developmental instability, good physical condition) to potential mates and intrasexual rivals. This might also relate to a general tendency for risk-taking displays by young males, a group for whom intra-sexual competition is particularly intense [38,39]. Circumstantial evidence for this idea is provided by tattoos being positively correlated with risk taking and sexual behaviours during late adolescence and young adulthood [40]. Likewise, a recent study demonstrated that women perceive tattoos on men as a signal of good health, and men more intensely perceive tattoos on other men as a signal of attractiveness, masculinity, aggressiveness and dominance [10].

Our finding that the overall number of tattoos correlated positively (rather than negatively) with FA in females is more difficult to explain but suggests that women who accumulate many 
tattoos are unlikely to do so for the purpose of signalling high DI. A possibility of course is that this effect is simply a spurious result of us using a cFA measure based upon only two pairs of traits. It is also notable that high L2D:4D was associated with a greater number of tattoos is females, as a previous study [41] observed that women (and men) who reported experiencing pain during the tattooing process had lower 2D:4D ratios than those who did not. Taken together, these findings could suggest that women who experience less pain are more likely to subsequently obtain additional tattoos. Another potential explanation relates to the masculinity/femininity personality domain, which is itself known to be associated with 2D:4D [42]. Essentially, high levels of femininity could be correlated with sexual signalling behaviours such as using tattoos to accentuate attractive body parts or as a means of hiding perceived shortcomings in appearance [7]. However, in the current context, this explanation is at best speculative and likely overly simplistic because the effect disappeared once covariates had been controlled for.

Concerns have been expressed regarding publication bias in both the FA [18] and 2D:4D [43] literatures. A strength of the current study therefore is that we pre-registered our hypotheses and analysis plan prior to collecting data. However, we also utilised self-measured finger lengths: Although reasonably accurate when obtained under lab conditions [44], the reliability of such measures in online studies appears to be quite low [45]. This is particularly problematic as FA and measurement error are essentially indistinguishable (both being normally distributed around a mean of zero) and because differences in the size of paired traits is typically so small that true differences can be obscured by inaccurate measurements [46]. However, it should be also be noted that we observed the well-established sex differences for 2D:4D [45] (i.e. males had significantly lower R2D:4D and L2D:4D, indicative of higher prenatal testosterone exposure) as well as the expected lack of sexual dimorphism for cFA, and that the relatively low reliability of self-measurement may be (at least to some extent) compensated for by our large sample size.

A further issue is that we did not record whether participants had ever broken their second or fourth fingers, information that would be useful considering that such injuries can influence finger length. Additionally, it should be acknowledged that we only included two traits $(2 \mathrm{D}$ and 4D) in our measure of composite FA, and that these may not be considered developmentally independent. Future research would therefore benefit from more reliable (i.e. researcher-measured) estimates of FA that are derived from a greater number of 
(developmentally-independent) traits [46]. We also encourage researches in this field (and others) to pre-register their studies when feasible, and to attempt publication regardless of the results obtained (for examples, see [47-49]).

\section{Conclusions}

The current study broadly replicates the finding of Koziel et al. [8] that tattooed males are more symmetrical than non-tattooed males. Although this may suggest tattoos can serve as a fitness indicator used by males to signal their biological quality to potential mates and intrasexual rivals, we also observed a positive correlation between FA and number of tattoos in females, an effect that warrants further exploration. 2D:4D was differentially associated with tattoo quantity, with low ratios predicting high numbers of tattoos in males and low numbers of tattoos in females. Although this could implicate prenatal testosterone involvement in the propensity for people to get tattoos, this interpretation may be erroneous because the effects disappeared once covariates had been controlled for statistically.

\section{Funding}

This research was supported by the School of $\operatorname{xxxx}, \operatorname{xxxx}$ University. The funders played no role in the study design, collection, analysis and interpretation of data, writing of the report, or the decision to submit the article for publication.

\section{Data statement}

The dataset supporting this article is available on the study's Open Science Framework page (https://osf.io/9zxty).

\section{Acknowledgements}

The authors would like to thank the participants of this study for making the research possible.

\section{Conflict of interest}

None declared.

\section{References}


[1] L. Krutak, The cultural heritage of tattooing: A brief history, in: J. Serup, N. Kluger, W. Bäumler (Eds.), Tattooed Ski. Heal., Karger Publishers, Basel, Switzerland, 2015: pp. 1-5. https://doi.org/10.1159/000369174.

[2] L. Dorfer, M. Moser, F. Bahr, K. Spindler, E. Egarter-Vigl, S. Giullén, G. Dohr, T. Kenner, A medical report from the stone age?, Lancet. 354 (1999) 1023-1025. https://doi.org/10.1016/S0140-6736(98)12242-0.

[3] J. Adams, Marked difference: Tattooing and its association with deviance in the United States, Deviant Behav. 30 (2009) 266-292. https://doi.org/10.1080/01639620802168817.

[4] J. Camacho, W. Brown, The evolution of the tattoo in defiance of the immutable definition of deviance: Current perceptions by law enforcement of tattooed arrestees, Deviant Behav. 39 (2018) 1023-1041. https://doi.org/10.1080/01639625.2017.1395669.

[5] P.S. Islam, C. Chang, C. Selmi, E. Generali, A. Huntley, S.S. Teuber, M.E. Gershwin, Medical complications of tattoos: A comprehensive review, Clin. Rev. Allergy Immunol. 50 (2016) 273-286. https://doi.org/10.1007/s12016-016-8532-0.

[6] J. Kazandjieva, N. Tsankov, Tattoos: Dermatological complications, Clin. Dermatol. 25 (2007) 375-382. https://doi.org/10.1016/j.clindermatol.2007.05.012.

[7] D. Singh, P.M. Bronstad, Sex differences in the anatomical locations of human body scarification and tattooing as a function of pathogen prevalence, Evol. Hum. Behav. 18 (1997) 403-416. https://doi.org/10.1016/s1090-5138(97)00089-5.

[8] S. Koziel, W. Kretschmer, B. Pawlowski, Tattoo and piercing as signals of biological quality, Evol. Hum. Behav. 31 (2010) 187-192. https://doi.org/10.1016/j.evolhumbehav.2009.09.009.

[9] C.D. Lynn, T. Puckett, A. Guitar, N. Roy, Shirts or skins?: Tattoos as costly honest signals of fitness and affiliation among US intercollegiate athletes and other undergraduates, Evol. Psychol. Sci. 5 (2019) 151-165. https://doi.org/10.1007/s40806018-0174-4.

[10] A. Galbarczyk, A. Ziomkiewicz, Tattooed men: Healthy bad boys and good-looking competitors, Pers. Individ. Dif. 106 (2017) 122-125. https://doi.org/10.1016/j.paid.2016.10.051.

[11] A. Zahavi, Mate selection-A selection for a handicap, J. Theor. Biol. 53 (1975) 205214. https://doi.org/10.1016/0022-5193(75)90111-3.

[12] L. van Valen, A study of fluctuating asymmetry, Evolution (N. Y). 16 (1962) 125-142. 
https://doi.org/10.1111/j.1558-5646.1962.tb03206.x.

[13] A.P. Møller, J.P. Swaddle, Asymmetry, developmental stability, and evolution, Oxford University Press, Oxford, UK, 1997.

[14] S. Van Dongen, Human bodily asymmetry relates to behavioral lateralization and may not reliably reflect developmental instability, Symmetry (Basel). 10 (2018). https://doi.org/10.3390/sym10040117.

[15] N. Pound, D.W. Lawson, A.M. Toma, S. Richmond, A.I. Zhurov, I.S. Penton-Voak, Facial fluctuating asymmetry is not associated with childhood ill-health in a large British cohort study, Proc. R. Soc. B Biol. Sci. 281 (2014) 20141639. https://doi.org/10.1098/rspb.2014.1639.

[16] R. Trivers, J.T. Manning, R. Thornhill, D. Singh, M. McGuire, Jamaican Symmetry Project: Long-term study of fluctuating asymmetry in rural Jamaican children, Hum. Biol. 71 (1999) 417-30. http://www.ncbi.nlm.nih.gov/pubmed/10380376.

[17] S. Van Dongen, Fluctuating asymmetry and developmental instability in evolutionary biology: Past, present and future, J. Evol. Biol. 19 (2006) 1727-1743. https://doi.org/10.1111/j.1420-9101.2006.01175.x.

[18] S. Van Dongen, S.W. Gangestad, Human fluctuating asymmetry in relation to health and quality: A meta-analysis, Evol. Hum. Behav. 32 (2011) 380-398. https://doi.org/10.1016/j.evolhumbehav.2011.03.002.

[19] J.H. Graham, B. Özener, Fluctuating asymmetry of human populations: A review, Symmetry (Basel). 8 (2016) 154. https://doi.org/10.3390/sym8120154.

[20] S. Wohlrab, B. Fink, P.M. Kappeler, G. Brewer, Perception of human body modification, Pers. Individ. Dif. 46 (2009) 202-206. https://doi.org/10.1016/j.paid.2008.09.031.

[21] J.M. Dabbs, M.G. Dabbs, Heroes, rogues, and lovers - testosterone and behavior, McGraw Hill, New York, NY, 2000.

[22] J.T. Manning, D. Scutt, J. Wilson, D.I. Lewis-Jones, The ratio of 2nd to 4th digit length: A predictor of sperm numbers and concentrations of testosterone, luteinizing hormone and oestrogen, Hum. Reprod. 13 (1998) 3000-3004. https://doi.org/10.1093/humrep/13.11.3000.

[23] G. Richards, What is the evidence for a link between digit ratio (2D:4D) and direct measures of prenatal sex hormones?, Early Hum. Dev. 113 (2017) 71-72. https://doi.org/10.1016/j.earlhumdev.2017.08.003.

[24] M. Leslie, The mismeasure of hands?, Science (80-. ). 364 (2019) 923-925. 
https://doi.org/10.1126/science.364.6444.923.

[25] T.C. Pratt, J.J. Turanovic, F.T. Cullen, Revisiting the criminological consequences of exposure to fetal testosterone: A meta-analysis of the 2D:4D digit ratio, Criminology. 54 (2016) 587-620. https://doi.org/10.1111/1745-9125.12115.

[26] F. Faul, E. Erdfelder, A.-G. Lang, A. Buchner, G*Power 3: A flexible statistical power analysis program for the social, behavioral, and biomedical sciences, Behav. Res. Methods. 39 (2007) 175-191. https://doi.org/10.3758/bf03193146.

[27] F. Faul, E. Erdfelder, A. Buchner, A.-G. Lang, Statistical power analyses using G*Power 3.1: Tests for correlation and regression analyses, Behav. Res. Methods. 41 (2009) 1149-1160. https://doi.org/10.3758/BRM.41.4.1149.

[28] J.C. Tate, B.L. Shelton, Personality correlates of tattooing and body piercing in a college sample: The kids are alright, Pers. Individ. Dif. 45 (2008) 281-285. https://doi.org/10.1016/j.paid.2008.04.011.

[29] S. Wohlrab, J. Stahl, T. Rammsayer, P.M. Kappeler, Differences in personality characteristics between body-modified and non-modified individuals: Associations with individual personality traits and their possible evolutionary implications, Eur. J. Pers. 21 (2007) 931-951. https://doi.org/10.1002/per.642.

[30] M. Tiggemann, L.A. Hopkins, Tattoos and piercings: Bodily expressions of uniqueness?, Body Image. 8 (2011) 245-250. https://doi.org/10.1016/j.bodyim.2011.03.007.

[31] S.O. Leung, M.L. Xu, Single-item measures for subjective academic performance, self-esteem, and socioeconomic status, J. Soc. Serv. Res. 39 (2013) 511-520. https://doi.org/10.1080/01488376.2013.794757.

[32] J.T. Manning, A.J.G. Churchill, M. Peters, The effects of sex, ethnicity, and sexual orientation on self-measured digit ratio (2D:4D), Arch. Sex. Behav. 36 (2007) 223233. https://doi.org/10.1007/s10508-007-9171-6.

[33] M. Peters, J.T. Manning, S. Reimers, The effects of sex, sexual orientation, and digit ratio (2D:4D) on mental rotation performance, Arch. Sex. Behav. 36 (2007) 251-260. https://doi.org/10.1007/s10508-006-9166-8.

[34] M. Voracek, Who wants to believe? Associations between digit ratio (2D:4D) and paranormal and superstitious beliefs, Pers. Individ. Dif. 47 (2009) 105-109. https://doi.org/10.1016/j.paid.2009.01.051.

[35] Office for National Statistics, Sexual orientation, UK: 2018, (2018). https://www.ons.gov.uk/peoplepopulationandcommunity/culturalidentity/sexuality/bull 
etins/sexualidentityuk/2018 (accessed October 20, 2020).

[36] D. Skowronski, M. Beisert, M. Nowicka, K. Halemba, A. Izdebska, S. SawczukSlupinska, The analysis of sexual lifestyles of adult Poles. Comparison of an internetbased survey and paper-based survey, Sexologies. 17 (2008) S56. https://doi.org/10.1016/S1158-1360(08)72669-0.

[37] Z. Izdebski, Seksualność Polaków na początku XXI wieku: Studium badawcze, Wydawnictwo Uniwersytetu Jagiellońskiego, Krakow, Poland, 2012.

[38] M. Wilson, M. Daly, Competitiveness, risk taking, and violence: The Young Male Syndrome, Ethol. Sociobiol. 6 (1985) 59-73. https://doi.org/10.1016/01623095(85)90041-x.

[39] M. Daly, M. Wilson, Homicide, Aldine de Gruyter, Hawthorne, NY, 1988.

[40] M. Deschesnes, P. Finès, S. Demers, Are tattooing and body piercing indicators of risk-taking behaviours among high school students?, J. Adolesc. 29 (2006) 379-393. https://doi.org/10.1016/j.adolescence.2005.06.001.

[41] S. Kozieł, R. Chakraborty, A. Sitek, Second to fourth digits ratio (2D:4D) and subjective pain experience in tattooing, Anthropol. Rev. 76 (2013) 117-124. https://doi.org/10.2478/anre-2013-0015.

[42] J.T. Manning, R. Trivers, B. Fink, Is digit ratio (2D:4D) related to masculinity and femininity? Evidence from the BBC Internet Study, Evol. Psychol. Sci. 3 (2017) 316324. https://doi.org/10.1007/s40806-017-0098-4.

[43] M. Voracek, S. Stieger, Replicated nil associations of digit ratio (2D:4D) and absolute finger lengths with implicit and explicit measures of aggression, Psicothema. 21 (2009) 382-989. http://www.ncbi.nlm.nih.gov/pubmed/19622317.

[44] G. Richards, T.K. James, A comparison of self-measured and researcher-measured digit ratio (2D:4D), Ann. Hum. Biol. 46 (2019) 527-530. https://doi.org/10.1080/03014460.2019.1674380.

[45] J. Hönekopp, S. Watson, Meta-analysis of digit ratio 2D:4D shows greater sex difference in the right hand, Am. J. Hum. Biol. 22 (2010) 619-630. https://doi.org/10.1002/ajhb.21054.

[46] A.R. Palmer, C. Strobeck, Fluctuating asymmetry analyses revisited, in: M. Polak (Ed.), Dev. Instab. Causes Consequences, Oxford University Press, Oxford, UK, 2003: pp. 279-319.

[47] G. Richards, S. Baron-Cohen, T. van Steen, J. Galvin, Assortative mating and digit ratio (2D:4D): A pre-registered empirical study and meta-analysis, Early Hum. Dev. 
151 (2020) 105159. https://doi.org/10.1016/j.earlhumdev.2020.105159.

[48] J. Wernicke, J.T. Zabel, Y. Zhang, B. Becker, C. Montag, Association between tendencies for attention-deficit/hyperactivity disorder (ADHD) and the 2D:4D digit ratio: A cross-cultural replication in Germany and China, Early Hum. Dev. 143 (2020) 104943. https://doi.org/10.1016/j.earlhumdev.2019.104943.

[49] G. Richards, W. V. Browne, E. Aydin, M. Constantinescu, G. Nave, M.S. Kim, S.J. Watson, Digit ratio (2D:4D) and congenital adrenal hyperplasia (CAH): Systematic literature review and meta-analysis, Horm. Behav. 126 (2020) 104867. https://doi.org/10.1016/j.yhbeh.2020.104867. 